\title{
The Role of International Law in the War on Illicit Drugs
}

\author{
Lloyd, Chidi Julius (JP), LLB, BL, LLM, PhD
}

Lecturer, University of Nigeria, Nsukka, Nigeria

Emails: chidiloyd@yahoo.com chidi.lloyd@unn.edu.ng, newmanenyioko@yahoo.com

\begin{abstract}
The paper evaluates the role of international law in the so-called fight against illicit drugs. It assesses the harm caused by the non-medicinal use of such drugs, finding that this does indeed exist but recognising that the very rendering of drugs as illicit may also cause such harm. The key harms here are human rights violations and the undermining of personal autonomy. The work argues that an effective framework for the control of drugs should seek to mitigate the harm associated with drug use with minimal restrictions on autonomy, but not itself introduce further harm. It submits that the international framework cannot be considered as effective in this regard, and that it is underpinned by Western notions of morality from the mid- $20^{\text {th }}$ Century rather than any objective assessment either of harm caused by drugs, or how best to regulate those drugs. The framework focuses on punishment and the limited recognition of the role of rehabilitation in reducing harm. It is shown that the framework does not envisage a clear role for States in managing the type of drug problems which they have experienced, notwithstanding the apparent commitment to State sovereignty, and that this is problematic, although this has not prevented some States from taking a different approach in respect of cannabis. However, it is shown that decriminalisation is not enough to ensure an effective approach or protection of human rights, and what is needed is a mitigation of the black market for drugs
\end{abstract}

Keywords: International Law, War on Illicit Drugs, Illicit Drugs, Combating Harm, Punishment, Rehabilitation 


\section{$\underline{\text { Introduction }}$}

In 2013, the European Court of Human Rights (ECtHR), in a case ${ }^{1}$ which considered the compatibility of the lengthy sentence and the manner of the trial of a prisoner transferred from Thailand to the UK for drug possession offences, ${ }^{2}$ pointed $^{3}$ to the Thai position that 'narcotics are an international concern and pose serious risks against human health and life' ${ }^{4}$ such that the punishment for offences related to illicit drugs, including possession, may be considered justifiably harsh. Indeed, regardless of questions relating to punishment, the United Nations (UN) Office on Drugs and Crime (UNODC) is clear that its remit in controlling the trafficking and distribution of illicit drugs is underpinned by a need to promote 'health, security and justice' ${ }^{5}$ in a context where, it asserts, drug related activity threatens to undermine these goals. ${ }^{6}$ Commentators such as Boister highlight that the aim of the international regime controlling illicit drugs is not simply to punish those involved in trading and using such drugs, ${ }^{7}$ but rather this exists as a corollary to a framework whose fundamental purpose is to "control" ${ }^{18}$ the trade in "non-medicinal"9 drugs.

That there is a clear international regime for the control of illicit drugs is axiomatic; the framework is, as Bewley-Taylor and Jelsma explain, 'multilateral'10 and made up of 3 key Treaties: the UN Single Convention on Narcotic Drugs (The Single Convention)

\footnotetext{
${ }^{1}$ Willcox and Hurford $v$ The United Kingdom [2013] ECHR 292 (Application Nos 43759/10 43771/12).

2 ibid, [2]-[35].

3 ibid, [41].

4 ibid.

${ }^{5}$ UNODC, 'About the United Nations Office on Drugs and Crime' (No Date Available) available at https://www.unodc.org/unodc/en/about-unodc/index.html accessed 15/2/2021.

6 ibid.

${ }^{7} \mathrm{~N}$ Boister, An Introduction to Transnational Criminal Law (Second Edition, Oxford University Press 2018) 89.

8 ibid.

9 ibid.

${ }^{10} \mathrm{D}$ Bewley-Taylor and M Jelsma, 'Regime Change: Re-Visiting the 1961 Single Convention on Narcotic Drugs’ (2012) 23 International Journal of Drug Policy 72-81, 72.
} 
1961, and the 1972 Protocol Amending the Single Convention; the Convention on Psychotropic Substances (CPN) 1971; and the Convention Against Illicit Traffic in Narcotic Drugs and Psychotropic Substances (1988 Convention) 1988. The rationale for the regime, Boister suggests, is one about which there is agreement, and again the primary aim is to ensure that drug use is medicinal only and that the trade and use of illicit drugs is prevented. ${ }^{11}$ The difficulty however, he argues, is that there is a divergence in the policy adopted by some States in relation to the stance taken on possession and use of drugs. ${ }^{12} \mathrm{~A}$ similar point is made by Bewley-Taylor, who suggests that notwithstanding the fact that the regime may be considered to be almost completely international, in the sense that participation in it by States is high, there is a 'growing' 13 inconsistency in the policy of States towards the objectives and indeed provisions of the applicable Treaties. ${ }^{14}$ The divergence may be explained, it is submitted, by an apparent disagreement about whether the best way to achieve the objectives of the regime is through restrictive control and harsh punishment, or through more liberal 'regulation'15 and indeed, it is suggested that this is hardly surprising given the large number of States participating in the regime and their different political stances. ${ }^{16}$

Moreover, there may be some evidence that the drafting of the Treaties may contribute to the extent to which this difference in stance is possible within the framework;

\footnotetext{
${ }^{11} \mathrm{~N}$ Boister, 'Waltzing on the Vienna Convention on Drug Control? Tensions in the International System for the Control of Drugs' (2016) 29(2) LJIL 389-409, 389.

12 ibid, passim.

${ }^{13}$ DR Bewley-Taylor, 'Towards Revision of the UN Drug Control Conventions: Harassing LikeMindedness' (2013) 24 International Journal of Drug Policy 60-68, 60.

14 ibid.

${ }^{15}$ The Global Commission on Drugs Policy, Regulation: The Responsible Control of Drugs (2018), 9, available at https://www.globalcommissionondrugs.org/wp-content/uploads/2018/09/ENG2018_Regulation_Report_WEB-FINAL.pdf accessed 15/2/2021. ${ }^{16}$ United Nations Treaty Collections (Updated 2020) available at https://treaties.un.org/pages/ViewDetails.aspx?src=TREATY\&mtdsg_no=VI-15\&chapter=6 accessed $15 / 2 / 2021$.
} 
Armenta and Jelsma highlight that the Treaties are in part worded flexibly such that there is no definitive requirement for States to impose criminal punishment for drug $u s e,{ }^{17}$ and it is suggested that this may explain why States have perhaps been able to adopt different policies. A further point here may be that, and more detail will be provided later in the work, the framework, whilst it does list different drugs for treatment in different ways, is drafted with a view to combating the illicit trade in those drugs, rather than controlling the drugs themselves. Given that, as the UNODC has explained, some drugs used recreationally, such as codeine and heroin, also have medicinal uses, ${ }^{18}$ and that these are regulated differently in different countries, ${ }^{19}$ it is submitted that it is again hardly surprising that treatment of such drugs in the illicit market is also likely to be different. In this regard, for example, the World Health Organisation (WHO) has recommended that the treatment of Cannabis be reconsidered under the international framework, ${ }^{20}$ and some States have indeed moved towards decriminalisation of the drug, notwithstanding the fact that there is evidence about the objective harm of cannabis use. ${ }^{21}$ This, it is suggested, raises questions about how far international law should seek to control harmful behaviour among individuals. A similar point may be made with respect to alcohol: there is myriad literature which confirms that the harmful effects of alcohol are similar to drugs which are generally

\footnotetext{
17 A Armenta and M Jelsma, 'The UN Drug Control Conventions' (2015) available at https://www.tni.org/en/publication/the-un-drug-control-conventions accessed 15/2/2021.

18 UNODC, Terminology and Information on Drugs (Third Edition 2016), 19, available at https://www.unodc.org/documents/scientific/Terminology_and_Information_on_Drugs-

E_3rd_edition.pdf accessed 15/2/2021.

${ }^{19}$ ibid.

${ }^{20}$ European Monitoring Centre for Drugs and Drug Addiction, 'WHO Recommends Rescheduling of Cannabis' (2019) available at http://www.emcdda.europa.eu/news/2019/who-recommendsrescheduling-of-cannabis_en accessed 15/2/2021.

${ }^{21}$ BP Smyth, M Cannon, A Molodynski, HV Curran and AR Winstock, 'Would Decriminalising Personal Use of Cannabis Lead to Higher Rates of Mental Illness?' [2020] BMJ available open access at https://www.bmj.com/content/368/bmj.16975 accessed 15/2/2021.
} 
considered to fall under the international framework in terms of illicit usage, ${ }^{22}$ and yet alcohol, although it is treated differently by different States in terms of its regulation, does not fall under that framework. ${ }^{23}$ This certainly raises questions in terms of not only how different substances should be treated, but whether the international framework for the regulation of illicit drugs is based on perceptions of the harm caused rather than their actual harm: if this is the case, it may also be that a different approach is likely to be taken in different States due to variances in such perceptions, either in terms of the drugs themselves or the best way to regulate them.

The above notwithstanding, it may be that whether States have been able to adopt different policies under an ostensibly global regime, is not necessarily an issue: given that the primary aim of the regime is to control the trade and use of illicit drugs and ensure that drugs are instead used for medicinal purposes only, it may be the case that a variety of mechanisms appropriate in different States may be possible within that underlying goal. Researchers for the UK Government in 2014 for example suggested that 'flexibil[ity]" ${ }^{24}$ is needed within the drug control framework in order to meet the changing nature of the illicit drugs market, and it does not seem unfeasible that the market may change not only progressively but at different rates and in different ways in various States. If the illicit drugs trade can be considered to be an 'evolving' 25 area, then it seems only prudent to ask whether the law should evolve similarly in order to respond to the challenges presented, and how far this should envisage a different

22 --, 'The Global Burden of Disease Attributable to Alcohol and Drug Use in 195 Countries and Territories, 1990-2016: A Systematic Analysis for the Global Burden of Disease Study 2016' (2018) The Lancet Open Access available at https://www.thelancet.com/journals/lanpsy/article/PIIS22150366(18)30337-7/fulltext accessed 15/2/2021.

23 ibid.

24 HM Government, Drugs: International Comparators (2014), 7, available at https://assets.publishing.service.gov.uk/government/uploads/system/uploads/attachment_data/file/3684 89/DrugsInternationalComparators.pdf accessed 15/2/2021.

25 ibid. 
approach in different States. The illicit drugs trade may be a global problem, ${ }^{26}$ but this cannot be considered as necessarily tantamount to an assertion that the problems posed by the trade are the same in all areas. ${ }^{27}$ As Giommoni and her colleagues have found, 'price mark ups tend to be lower in destination countries with high levels of corruption' ${ }^{28}$ If this is the case, it does not seem unreasonable to ask whether the political, social and economic factors in different States may affect the illicit drug trade, and thus the type of response which is appropriate in those States in order to satisfactorily achieve the aims of the international framework, or if what is really needed is a "co-ordinated" ${ }^{29}$ and harmonized international response to illicit drugs.

\section{Research Questions}

The study considered these research questions:

- What role, if any, should international law play in regulating the use of drugs for non-medicinal purposes, and to what extent is the current regime compatible with this?

- What is the harm caused by non-medical uses of drugs (drugs v illicit drugs)?

- Is combating harm from drugs effective through punishment, rehabilitation and human rights?

\footnotetext{
${ }^{26}$ UNODC, 'Drug Trafficking' (No Date Available) available at https://www.unodc.org/unodc/en/drug-trafficking/index.html accessed 15/2/2021.

${ }^{27}$ L Giommoni, A Aziani and G Berlusconi, 'How do Illicit Drugs Move Across Countries? A Network Analysis of Heroin Supply to Europe' (2017) 47(2) Journal of Drug Issues (217-240) 1-23 (online page numbering), 4 .

28 ibid.

${ }^{29}$ European Commission, 'Migration and Home Affairs' (Updated 2020) available at https://ec.europa.eu/home-affairs/what-we-do/policies/organized-crime-and-human-trafficking/drugcontrol/ic_en accessed 15/2/2021.
} 


\section{Methodology}

The research was entirely desk based, and it became necessary to evaluate the context within which international law takes place, pursuant to assessing whether illicit drugs should be regulated and for what reasons. This necessitated a consideration of the role of law in society. In order to consider the effectiveness of the framework, the work undertook analysis of primary sources including international Conventions, domestic law and relevant case law. The discussion was however simply doctrinal as the work assessed the effectiveness of the law against its rationale, and this was supported by synthesis of academic, industry and in part, scientific commentary. 


\section{The Role International Law Plays in Regulating the Use of Drugs for Non- Medicinal Purposes}

It is clear that the international framework on illicit drugs exists pursuant to combating trade in such drugs $;{ }^{30}$ indeed it was noted in the introductory chapter that there appears to be something of a 'consensus' ${ }^{31}$ between commentators and States alike, that the purpose of the regime here is to prevent drugs being developed, moved and subsequently used, for purposes which are non-medicinal. This certainly seems to be the case, and further evidence can be found in the work of the UNODC, whose Economic and Social Council has been repeatedly clear that the aim of the international regime is to ensure that States act consistently to combat the illicit drugs trade, in the context of an 'efficient' ${ }^{32}$ international regime. The issue however, is that the fact that this is the aim of the international regime, and the content of the law and its effectiveness will be evaluated in chapters 3 and 4 of this work, has no bearing on whether there should be such a regime or what an effective approach in the context of regulating illicit drugs should comprise. In order to determine whether this is in fact the case, the starting point must be to consider the market for illicit drugs and its operation as a transnational crime.

\footnotetext{
${ }^{30} \mathrm{~N}$ Boister, An Introduction to Transnational Criminal Law (Second Edition, Oxford University Press 2018) 89.

${ }^{31} \mathrm{~N}$ Boister, 'Waltzing on the Vienna Convention on Drug Control? Tensions in the International System for the Control of Drugs' (2016) 29(2) LJIL 389-409, 389.

${ }^{32}$ UNODC Economic and Social Council, 1991/47 United Nations International Drug Programme (1991) $15^{\text {th }}$ Plenary Meeting available at https://www.unodc.org/unodc/en/Resolutions/resolution_1991-0621_9.html accessed 15/2/2021.
} 
In this regard, the UN 2019 World Drug Report presents the findings of research which suggests that in 2017 in excess of 585,000 people died worldwide due to illicit drug use. ${ }^{33}$ It is true that this figure is somewhat misleading in isolation, and that the report does not discuss the proportion of those deaths which may have occurred regardless or the contributory effect of other factors; it simply claims that ' 42 million years of "healthy" lives" ${ }^{34}$ were lost due to drugs. There is little information here about how these lives are harmed due to drugs, and thus again the figures do not seem helpful in isolation. Further information is provided by researchers at the University of Oxford, who state that illicit drug use leads to 750,000 deaths per year either 'directly or indirectly, ${ }^{35}$ highlighting that the figure of 585,000 deaths above is attributable to illness and 'injury' ${ }^{36}$ which has occurred as a result of drug use. The researchers define indirect results of drug use as including the sorts of deaths above, with direct results being deaths which occur from overdose or drug addiction. ${ }^{37}$ As some sources claim that drug use is increasing, ${ }^{38}$ it may seem reasonable to conclude that illicit drug use, which as shown above clearly causes harm to people, is problematic and results in large numbers of deaths. Indeed, when viewed over time, there is some evidence that illicit drug use has grown exponentially, at least in respect of some drugs, and that those which appear to have reduced in terms of usage have nevertheless grown in 'potency', ${ }^{39}$ such that data suggesting a reduction in usage may be misleading.

\footnotetext{
33 UN World Drug Report 2019 Executive Summary, available at https://wdr.unodc.org/wdr2019/en/exsum.html accessed 15/2/2021.

34 ibid.

${ }^{35}$ H Ritchie and M Roser, 'Opioids, Cocaine, Cannabis and Illicit Drugs' (Updated 2019) Our World in Data available at https://ourworldindata.org/illicit-drug-use accessed 15/2/2021.

36 ibid.

${ }^{37}$ ibid.

38 --, 'The History of Drug Abuse and How It's Changed' (Updated 2020) Foundations Recovery Networks available at https://dualdiagnosis.org/the-history-of-drug-abuse-and-how-its-changed/ accessed 15/2/2021.

39 ibid.
} 
This may say more about the lack of effectiveness of the regime itself rather than the illicit drugs market, given that the purpose is to reduce drug use, but what does appear to be clear is that whilst there is difficultly in assessing the true extent of the problem, drug use causes harm to individuals. As Shiner is clear, although he recommends less 'punitive response ${ }^{40}$ to combating drug use, the consumption of drugs for non-medical purposes causes objective and significant harm to individuals. ${ }^{41}$ Despite recognising this harm, a UN Report however paints a different picture of trends in drug usage; in 2008 it found that use of heroin and cocaine had significantly reduced over the last century, ${ }^{42}$ citing this as evidence of the efficacy of the international regime on combating the illicit drugs market, ${ }^{43}$ and as an argument for ensuring on-going commitment to that regime. ${ }^{44}$ Again, the nature of the regime will be considered later in the work, although it is observed here that given the report's aim of demonstrating the effectiveness of the regime, one must take its conclusions with some caution. It remains the case that estimates show that in 2020 alone and at the point of writing, more than $£ 115,547,720$ has been spent worldwide on illicit drugs ${ }^{45}$ and that whilst estimating the size of the market compared to other legitimate markets is difficult due to the lack of availability of reliable data, ${ }^{46}$ the market does appear to be 'booming, ${ }^{47}$

\footnotetext{
${ }^{40}$ M Shiner, 'Out of Harm's Way? Illicit Drug Use, Medicalisation and the Law' (2003) 43(4) Brit J Criminol 772-796, 772-773.

41 ibid passim.

42 UNODC, A Century of International Drug Control: 100 Years (2008), 3, available at https://www.unodc.org/documents/data-and-analysis/Studies/100_Years_of_Drug_Control.pdf accessed 15/2/2021.

43 ibid.

44 ibid.

45 Worldometer, 'Spending on Illegal Drugs' (15/2/2021) available at https://www.worldometers.info/drugs/ accessed 15/2/2021.

46 UNODC, 'Estimating the Value of Illicit Drugs Markets' (2005) World Drug Report Volume I (Analysis), Chapter II, 123.

${ }^{47}$ E Gayle, 'Illegal Drug Market is Booming, Says UN Watchdog' (2017) The Guardian available at https://www.worldometers.info/drugs/ accessed 15/2/2021.
} 
Despite the difficulty in finding reliable data to compare market size, in the UK for example, researchers at the British Medical Journal found that in 2018, 8.5\% of adults claimed to have used illicit drugs; ${ }^{48}$ data provided by the Office of National Statistics (ONS) shows that in 2017, 57\% of persons over 16 drank alcohol in the week prior to the survey, ${ }^{49}$ and that only $20 \%$ of persons in that category considered themselves to be teetotal. ${ }^{50}$ It does seem therefore that use of alcohol far outweighs the use of illicit drugs, although there may be issues with reporting given the non-lawful nature of drug use. ${ }^{51}$ Given that there is evidence that deaths in which alcohol was a risk factor far outweigh those from illicit drugs, ${ }^{52}$ and that alcohol is consistently excluded from UNOCD data on the harm caused by substance abuse,${ }^{53}$ it does seem that whilst the market certainly seems to be extensive, it is less than other markets which seem to cause more harm, and thus the justification for an international legal regime against illicit drugs but excluding alcohol seems questionable. This will be discussed further shortly in terms of the morality underpinning the international framework.

A further point here is that the mere fact that something causes harm is not sufficient reason to criminalise it, and criminality must balance a legitimate need to prevent harm to society with respect for the autonomy of individuals. In this regard, the UNODC is

\footnotetext{
48 --, Reducing Harm Associated With Illicit Drug Use' (2018) British Medical Association (BMA) available at https://archive.bma.org.uk/collective-voice/policy-and-research/public-and-populationhealth/illicit-drug-use accessed 15/2/2021.

49 ONS, 'Dataset: Adult Drinking Habits in Great Britain' (2018) available at https://www.ons.gov.uk/peoplepopulationandcommunity/healthandsocialcare/drugusealcoholandsmoki ng/datasets/adultdrinkinghabits accessed 15/2/2021.

50 ibid.

${ }^{51}$ L Harrison and A Hughes, 'The Validity of Self-Reported Drug Abuse: Improving the Accuracy of Survey Estimates' (1997) US Department of Health and Human Services NIH Publication Number 974147, passim, available at https://archives.drugabuse.gov/sites/default/files/monograph167_0.pdf accessed 18/2/2021.

52 H Ritchie and M Roser, 'Drug Use' (2019) Our World in Data available at https://ourworldindata.org/drug-use accessed 15/4/2020.

53 UNODC, Drug Statistics And Trends (2010), passim, available at https://www.unodc.org/documents/wdr/WDR_2010/2.0_Drug_statistics_and_Trends.pdf accessed $15 / 2 / 2021$
} 
clear that the 'actions of rational persons" ${ }^{54}$ must be respected and that this is a foundational ethical principle about which there is a relative consensus. ${ }^{55}$ It is clear that drug use does cause harm to individuals but those individuals, where they are autonomous and thus capable of making their own decisions, however unwise, should be free to make those decisions without interference. ${ }^{56}$ Paternalistic policies which aim to reduce harm to individuals from certain practices fundamentally conflict with the principle of autonomy ${ }^{57}$ and this may suggest therefore that there is no justified role for international law in regulating drugs, at least in so far as this role comprises preventing individuals from exercising personal choice. As Buchanan observes, paternalism starts from the position that 'one is right, and therefore justified in seeking to override other people's judgment [and consequently] treats them as less than moral equals' ${ }^{58}$ Aside from the moral implications here, a more practical problem is particularly clear if one accepts the assertions of Buchanan that paternalistic policies which aim to control the behaviour of individuals, ostensibly to prevent harm, may reduce the extent to which those who undertake harmful practices choose to engage with the State where assistance, particularly in health matters, is needed. ${ }^{59}$

Given that it has been shown that objective harm results from drug use, this certainly seems problematic, and this may be exacerbated again by the fact that there is an emphasis within the human rights framework on respect for individual autonomy. ${ }^{60}$

\footnotetext{
${ }^{54}$ UNODC, Ethical Challenges in Drug Epidemiology: Issues, Principles and Guidelines (2004), 6, available at https://www.unodc.org/pdf/gap_toolkit_module7.pdf accessed 18/2/2021.

55 ibid.

${ }^{56}$ DR Buchanan, 'Autonomy, Paternalism and Justice: Ethical Priorities in Public Health' (2008) 98(1) Am J Public Health 15-21, online version no page numbers available.

57 ibid.

58 ibid.

59 ibid.

${ }^{60}$ A Marks, 'Defining "Personal Consumption" in Drug Legislation and Spanish Cannabis Clubs' (2019) 68(1) ICLQ 193-233, 218-219.
} 
This is clear for example from Article 1(1) of the International Covenant on Civil and Political Rights (ICCPR) 1966 which contains the right to 'self-determination', ${ }^{61}$ and the International Convention on Economic, Social and Cultural Rights (ICESCR) 1966, which is framed with the same language. ${ }^{62}$ Again therefore, one might be inclined towards such a conclusion that notwithstanding the objective harm which is caused from the consumption of drugs for non-medical purposes, the law, whether international or at domestic level, should not have a role in controlling that use.

However, it is submitted that such a conclusion is too simplistic: firstly, there is evidence that many users of drugs for such purposes are not truly autonomous in the sense that their decision to use drugs is a result of either addiction or social factors which prohibit the making of truly autonomous decision making. ${ }^{63}$ Whilst the psychology of addiction and the point at which the autonomous individual loses the ability to make such decisions is beyond the scope of this work, this does at least demonstrate that simply arguing that there should be no role for international law in regulating the non-medicinal use of drugs does not recognise all the potential arguments. Further, although interfering with the choices of the individual might be morally objectionable where that individual is indeed autonomous, it should be remembered that autonomy is not an ethical principle which exists in isolation and that a balance must be sought between protecting the autonomy of the individual and reducing the overall harm to public health and society which may result from certain

\footnotetext{
${ }^{61}$ ICCPR, Article 1(1).

${ }^{62}$ ICESCR, Article 1(1).

${ }^{63}$ F Koopmans and S Sremac, 'Addiction and Autonomy: Are Addicts Autonomous?' (2011) 9(1) Nova Prisutnost 171-188, 172.
} 
behaviours. ${ }^{64}$ Given that there is evidence of such harm, both economic and social, ${ }^{65}$ it is argued that in determining the role for international law in respect of controlling the production, marketing and use of drugs for non-medicinal purposes a balance should be sought between respecting autonomy and reducing harm to society. This point will as such underpin the discussion throughout the remainder of the work.

\section{The Harm Caused by Non-Medical Uses of Drugs (Drugs v Illicit Drugs)}

It has been argued throughout the work that there is a clear and objective harm which results from the use of drugs for non-medical purposes, and that it is preventing this use which has underpinned the international framework, although the content of that framework has not been discussed. This does not mean however that the role for international law has been to prevent the use of drugs only because they cause such objective harm, or indeed that the use of drugs is the only manner in which harm results from non-medical drug use.

In terms of the first point, if one traces the history of the development of the illicit drugs control regime, even before the advent of the current framework, it seems clear that it began when a newly economically and politically powerful United States of America was able to assert its views about drugs onto other States which had traditionally 'operated lucrative drug[s]' ${ }^{66}$ markets, particularly in terms of relations with China and

\footnotetext{
${ }^{64}$ DR Buchanan, 'Autonomy, Paternalism and Justice: Ethical Priorities in Public Health' (2008) 98(1) Am J Public Health 15-21, online version no page numbers available.

65 LC Claridge, 'Drugs and Harm to Society' (2011) The Lancet open access available at https://www.thelancet.com/journals/lancet/article/PIIS0140-6736(11)60194-3/fulltext accessed $15 / 2 / 2021$

${ }^{66} \mathrm{M}$ Jelsma, The Development of International Drug Control: Lessons Learned and Strategic Challenges for the Future (2011) Working Paper Prepared for the First Meeting of the Commission (Global Commission on Drugs Policies) Geneva Number 24-25, 2, available at https://www.tni.org/files/The\%20Development\%20of\%20International\%20Drug\%20Control_M.Jelsm a2011.pdf accessed 15/2/2021.
} 
India. This was a moral approach to the use of certain drugs, rather than an approach consistent with preventing objective harm. ${ }^{67}$ Indeed, by the 1960 s when the current regime was first developed, it was clear, and this is explained by Jelsma, ${ }^{68}$ that Western States initiating the Single Convention were motivated by a mistrust of Eastern practices in using Opium for medicinal purposes. ${ }^{69}$ It is true of course that the fact that the regime developed in such a context is not itself an argument that international law should not have a role in regulating the illicit drugs trade and the ability of States to mitigate harms caused to their citizens by the use of such drugs, balanced with respect for autonomy. Rather, it simply offers an explanation for the apparent difference in treatment of harmful drugs such as alcohol, treated favourably by Western States, ${ }^{70}$ and other drugs which are covered by the regime. It was shown earlier in the work that the illicit drugs market does not include substances such as alcohol which do cause objective harm and this therefore offers an explanation for such an approach, although not one which suggests an effective role for international law. It is suggested, building on the points about the balance between autonomy and preventing societal harms in the previous section, that the motive of international law should be to prevent objective harm to society rather than harm defined from the State's moral viewpoint, and that this better achieves respect for autonomy without seeking to 'override'71 the moral choices of individuals on a paternalistic basis.

\footnotetext{
67 ibid.

68 ibid 4.

69 ibid.

70 ibid.

${ }^{71}$ DR Buchanan, 'Autonomy, Paternalism and Justice: Ethical Priorities in Public Health' (2008) 98(1) Am J Public Health 15-21, online version no page numbers available.
} 
A further point here may be found in the work of Barnett. The commentator highlights that drug prohibition is intertwined with moral arguments. ${ }^{72} \mathrm{He}$ argues however that allowing morality to underpin regulation has meant that in addition to the harms which exist as a direct result of the substance, further harms exist merely by virtue of 'the fact that such drugs are illegal' ${ }^{73}$ This point is also made by Boister, who explains that harms which result from non-medical drug usage include crime to "fund" 74 the use of drugs, such that drug usage is a driving factor behind other crimes. He is clear that the market in illicit drugs, from cultivation and production through to transportation, marketing and use is responsible for a "range of harms ${ }^{\text {,75 }}$ although he recognises that rendering drugs illicit rather than legal may also cause such harms, particularly in respect of human rights including the restriction of autonomy, the lack of control of the content of drugs and the "endemic" ${ }^{76}$ corruption which is associated with the market. Writing elsewhere, Boister argues that because the drug trade operates across borders and is thus a transnational crime, the type of harm which results occurs in a number of States and thus, to prevent societal harm in the manner discussed above, there must be co-operation or a harmonized international approach. ${ }^{77}$ Whether this is too simplistic an assertion will be considered later in the work. At this point, it is merely clear, again returning to the work of Barnett, that in criminalising the drug market, ${ }^{78}$ users are not only exposed to 'unregulated' 79 products in drugs as discussed above, but also make

\footnotetext{
${ }^{72}$ RE Barnett, 'The Harmful Side Effect of Drug Prohibition' [2009] Utah Law Review 11-34, 11-12.

${ }^{73}$ ibid 17.

${ }^{74} \mathrm{~N}$ Boister, An Introduction to Transnational Criminal Law (Second Edition, Oxford University Press 2018) 89.

75 ibid 90.

76 ibid.

${ }^{77} \mathrm{~N}$ Boister, 'The Concept and Nature of Transnational Criminal Law' in N Boister and RJ Currie (eds), Routledge Handbook of Transnational Criminal Law (Routledge 2014) 11.

${ }^{78}$ RE Barnett, 'The Harmful Side Effect of Drug Prohibition' [2009] Utah Law Review 11-34, 17.

${ }^{79} \mathrm{~N}$ Boister, An Introduction to Transnational Criminal Law (Second Edition, Oxford University Press 2018) 90.
} 
purchases in dangerous situations; ${ }^{80}$ funds are directed into enforcing the laws rather than mitigating the harms caused from the drugs themselves; and violence and corruption grow. ${ }^{81}$ This point will be discussed later; here, it is simply observed that this adds a further dimension to the points about respecting autonomy above: if there is a justified role for international law in preventing societal harm, even though there is a restriction on autonomy, it must be the case that in order to be considered effective, that role should not itself cause further harm. Indeed, it may seem logical at this point to suggest that if it is the rendering of drugs illicit that is the problem, there should be no role for international law in the regulation of drugs, particularly again given the undermining of autonomy discussed earlier.

Commentators such as Palmer however do not find such arguments persuasive: Palmer recognises that the use of drugs causes harm but suggests that rather than attempting to mitigate this harm by decriminalisation, a more effective use of resources might be to tackle societal issues which create the demand for substances, and in doing this, a combination of methods, in terms of the role taken by the law, is likely to be more effective. ${ }^{82}$ He thus points out that 'demand reduction interventions ${ }^{83}$ will work more effectively in a context whereby there is a limitation on supply as well, and this seems to envisage a balance between preventing harm which arises through drug use and ensuring that regulation itself does not cause further harm. Such points will be considered in respect of the effectiveness of the international regime in the next chapter. At this point however, it is simply observed that the mere fact that there does seem to

\footnotetext{
${ }^{80}$ ibid.

${ }^{81}$ ibid.

${ }^{82}$ M Palmer, 'Editorial: Reducing the Supply of Illicit Drugs' (1998) 17 Drug and Alcohol Review 245-247, 246.

83 ibid.
} 
be issues with criminalisation, in that regulation can be harmful in a similar way to the very usage of drugs, is not sufficient to form the basis of an argument that international law should not have a role in regulating drug use, and that a more effective role will be to ensure that the law only operates to reduce societal harm and does not itself introduce further harms associated with rendering drugs illicit. Thus, the focus of the law should not be on the apparent lack of morality of engaging with substances rendered illicit by the law, but rather on ensuring that objective physical and psychological harm does not result from drug use and regulation across society as a whole.

It was noted above that commentators such as Boister have suggested that, in order to be effective, the role for international law should be one which is co-ordinated. ${ }^{84}$ It should be observed however that even from a purely practical perspective, the different principles and arrangements of legal systems in different States may make co-operation and thus enforcement difficult; as Obokata and Payne observe, a 'shared history and common law tradition ${ }^{85}$ has made co-operation between Ireland and the UK pursuant to combating illicit drugs and the trade therein easier than it might otherwise have been, and this might not apply in States with very different legal systems. There may be an objective justification for seeking to tackle the illicit drugs market, but this is not the same as there being a clear role for international, as opposed to domestic, law in this regard despite the nature of the market as being transnational. This rather suggests, it is submitted, that Boister's points earlier that where crime is transnational, a co-ordinated international response is always required in order to address the problem effectively, ${ }^{86}$

\footnotetext{
${ }^{84} \mathrm{~N}$ Boister, 'The Concept and Nature of Transnational Criminal Law' in N Boister and RJ Currie (eds), Routledge Handbook of Transnational Criminal Law (Routledge 2014) 11.

${ }^{85}$ T Obokata and B Payne, Transnational Organised Crime: A Comparative Analysis (Routledge 2018) 3.7.

${ }^{86} \mathrm{~N}$ Boister, 'The Concept and Nature of Transnational Criminal Law' in N Boister and RJ Currie (eds), Routledge Handbook of Transnational Criminal Law (Routledge 2014) 11.
} 
are too simplistic, although again this will be assessed in more detail later in the work. In any event, it should be observed that commentators such as Nadelmann have argued that the real problem with developing an effective international regime to combat illicit drugs is not the extent to which States exercise true commitment to that regime or indeed that co-operation is always the best policy, but rather the "vulnerability of the activity to its enforcement measures' ${ }^{87}$ Whilst this work does not aim to undertake a sociological argument of whether the criminal law is capable of altering the behaviour of those who market and use drugs, it must be remembered that the law does not operate in isolation and that its effectiveness will always be limited in this way.

To what extent can drugs such as cannabis justifiably be treated differently in different States within an effective international framework, which balances control with respect for rights?

\section{Effectiveness of Combating Harm from Drugs through Punishment, Rehabilitation and Human Rights}

It is noted that even though it has been shown that the international law aims to prevent drugs from being used for illicit purposes, this says nothing about the mechanisms which are appropriate to do this, or indeed what issues must be balanced within such an aim. In this regard, it has been noted above that where drugs are made illicit, as Boister explains, a number of harms may occur and these include the potential infringement of human rights, notably in terms of personal autonomy as discussed

\footnotetext{
${ }^{87}$ EA Nadelmann, 'Global Prohibition Regimes: The Evolution of Norms in International Society’ (1990 44(4) International Organisation 479-526, 479.
} 
earlier. ${ }^{88}$ In support of his comments here, Boister cites ${ }^{89}$ the report produced by the UN on the interplay between the illicit drug framework and human rights. The report discusses the outcome of a study conducted in this respect and it is true that it does seem to confirm such arguments. The report notes for example that the right to health ${ }^{90}$ might be undermined by the prohibition on drugs in the sense that users may be unwilling to admit their illicit activity to healthcare providers; ${ }^{91}$ that discrimination may occur as a result of liability being imposed for drug offences, ${ }^{92}$ and that this may particularly affect women, ${ }^{93}$ and children. ${ }^{94}$ Indeed, the report makes a direct link ${ }^{95}$ between making drugs illicit and the undermining of Article 33 of the UN Convention on the Right of the Child 1989 (UNCRC), which provides that States must take action to make sure that children are not involved in the 'production and trafficking' ${ }^{96}$ of illicit drugs. The problem however is that the report simply notes that the rights of the child may be triggered, in that children may be involved in illicit drug practices; ${ }^{97}$ that 'women who use drugs are more often the targets of violence' 98 than those who do not; and that many women engage in sex work due to the effects of drugs. ${ }^{99}$ This seems entirely descriptive such that the report does not draw a distinction here between the effect of drugs themselves in terms of these problems, and the effect of the illicit drug regime in this regard.

\footnotetext{
${ }^{88} \mathrm{~N}$ Boister, An Introduction to Transnational Criminal Law (Second Edition, Oxford University Press 2018) 90.

89 ibid.

${ }^{90}$ UN General Assembly Human Rights Council, Study on the Impact of the World Drug Problem on the Enjoyment of Human Rights (2015) UN DOC A/HRC/30/65, Section II.

${ }^{91}$ ibid Section II, Part D, notably at Paragraph 24.

92 ibid Section IV, Paragraph 50.

93 ibid Section IV, Part B, throughout.

94 ibid Section V.

95 ibid, Section V, Paragraph 55.

${ }^{96}$ UNCRC, Article 33.

${ }^{97}$ UN General Assembly Human Rights Council, Study on the Impact of the World Drug Problem on the Enjoyment of Human Rights (2015) UN DOC A/HRC/30/65, Section V, Paragraphs 55-57.

98 ibid, Section VI, Part B, Paragraph 54.

99 ibid.
} 
As it has been shown in this paper that consideration of such a distinction is necessary in order to develop an effective role for international law, this must be considered problematic. As it is, the failure to make such a distinction in the report means that it is difficult to assess how far the effects on human rights occur from the use of drugs and therefore offer more support for the role of international law being to prevent harm to society, or from the regime itself, which might suggest that there should not be a role here. As such, it cannot be accepted that the report is useful in supporting Boister's arguments that it is the illicit nature of drug use rather than just the use of drugs, which has this impact on human rights, regardless of the commentator's assertions here. ${ }^{100}$

In this regard and with a view to determining the interplay between human rights violations and the regulation of drugs, it is useful to consider the work of Nizami in his assessment of other work done in this area. Nizami also points to the link between 'making drugs illicit and black marketing', ${ }^{101}$ and that given that black market operations may lead to infringements of human rights, there is a clear interplay between the two areas. This appears in line with the work of Boister earlier in terms of the effect of making drugs illicit. In this context, Barrett points to views that human rights Treaties and the international law on illicit drugs, and he refers specifically to the UNCRC here, are 'mutually reinforcing' ${ }^{102}$ in the sense that the international framework operates to prevent the use of drugs other than for medical purposes because inter alia this might violate human rights, and the UNCRC not only confirms this in relation to children but

\footnotetext{
${ }^{100} \mathrm{~N}$ Boister, An Introduction to Transnational Criminal Law (Second Edition, Oxford University Press 2018) 90 .

${ }^{101}$ SQ Nizami, 'Confronting Drug Policy: Illicit Drugs in a Free Society: Book Review' (1997) 45(9) Social Science and Medicine 1461, 1461.

102 D Barrett, 'Canada, Cannabis and the Relationship Between UN Child Rights and Drug Control Treaties’ (2019) 71 International Journal of Drug Policy 29-35, 30.
} 
ensures that they are not able to be included in the process of bringing such drugs to market. They therefore, Barrett claims, 'mirror each other' ${ }^{103}$ and thus offer protection for specific human rights. What he seems to be saying, it is argued, is that the anti-drugs framework may contribute to respect for human rights and it is submitted that this argument cannot be accepted. It is true that the aim of the law seems to be to prevent drugs being used for non-medicinal purposes and that the UNCRC, as highlighted above, makes direct reference to this.

However, the focus on the illicit nature of drugs rather than the objective harm which has been shown earlier to be associated with drug use rather than merely criminalisation, means that all the provisions seem to be saying is that there should be protection from the very things which the law has itself created, the illicitness associated with the drugs. In this regard, support may be taken from Lines and his colleagues writing in a special edition for the Health and Human Rights Journal in 2017; the commentators present evidence that 'drug control and enforcement activities, are prime evidence for human rights abuses ${ }^{104}$ largely due to the fact that punishment, prohibition and enforcement mechanisms demonstrate 'actual evidence of human rights violations committed in the course of enforcing various drug-related laws' ${ }^{105}$ The operation of penal rules can create such violations in that they direct activities underground, creating criminal behaviour as opposed to simply objectively unwise choices and this has implications for human rights. ${ }^{106}$ Similarly, it was noted above that the UNCRC aims to prevent children from being involved in the illicit drugs market, a

\footnotetext{
103 ibid.

${ }^{104}$ R Lines, R Elliott, J Hannah, R Schleifer, T Avafia and D Barrett, 'Editorial: The Case for International Guidelines on Human Rights and Drug Control' (2015) 19(1) Health and Human Rights Journal 19(1) 231-236, 232.

105 ibid.

106 ibid passim.
} 
market which the regime itself created. It is argued that this is persuasive on the basis that, as shown throughout the work, there is not only an infringement of autonomy whenever the law intervenes with the choices of the individual, but when behaviours are rendered unlawful, the activities associated with that behaviour necessarily become illicit and thus, more dangerous. That is not to say that there is no harm associated with the use of non-medicinal drugs themselves which may justify a role for international law, and this was discussed earlier in the work. Rather, because, and again this has been shown above, making drugs illicit contributes to other types of harm, a framework developed in this way must be considered problematic, unless it seeks to achieve a balance between respecting the individual, protecting human rights, and preventing drug use where that use is harmful to society, whilst minimising the harm which may be associated with the very act of criminalisation.

Support here can be taken from the UN Development Programme (UNDP) which found in 2019 that punitive illicit drug frameworks undermine human rights and cause harm to individuals, and this must be taken into account in the exercise of an effective framework. ${ }^{107}$ Indeed, guidance produced inter alia by the WHO together with the UNDP confirms this analysis in that whilst it does not state that the current framework, and again evaluation of the framework itself will be considered later in the work, necessarily violates human rights norms, it does make it clear that an effective role for an international framework on illicit drugs implemented by States must 'not be used as a basis for violating concomitant human rights obligations'. ${ }^{108}$ Again, this does not

107 --, 'Landmark International Guideline Launched on Human Rights and Drug Policy' (2019) UNDP available at https://www.undp.org/content/undp/en/home/news-centre/news/2019/human-rights-anddrug-policy.html accessed 16/2/2021.

${ }^{108}$ International Centre on Human Rights and Drug Policy, the Joint UN Programme on HIV and Aids, WHO and UNDP, International Guidelines on Human Rights and Drug Policy (2019), V(1))iii). 
mean that the current framework does this but rather, it is simply argued that in order to be effective respecting human rights should be part of the international framework, and that given that it has been shown that there is a potential for undermining human rights through making certain drugs illicit, an effective framework must not only take this into account but mitigate the harm caused here. If it can be shown, and the discussion above demonstrates that it can, that the use of drugs can cause harm and undermine human rights rather than simply the regime, it is submitted that this is a clear argument in favour of there being a role for international law but underpinned by notions of harm reduction rather than necessarily criminal liability.

The above may also have implications in terms of the impact of punishment and how far the human rights framework and the regulation of drugs regime should operate in isolation. In this regard, Golichenko, Stolz and Ezer highlight not only that there is an evident interplay between illicit drug policies which seek to punish and the undermining of human rights, ${ }^{109}$ and indeed this has already been assessed above, but that seeking to enforce the regime through such punishment may further undermine such rights. ${ }^{110}$ They highlight ${ }^{111}$ comments made by the Special Rapporteur, who in 2008 advocated a strict separation between human rights law and the international framework on illicit drugs, ${ }^{112}$ asserting that this fundamentally misunderstands the impact on human rights, not simply from the use of drugs but from any involvement of international law in a

\footnotetext{
${ }^{109}$ M Golichenko, S Stolz and T Ezer, 'Addressing Human Rights Abuses Against People Who Use Drugs: A Critical Role for Human Rights Treaty Bodies and Special Procedures' (2018) 10 Journal of Human Rights Practice 83-102, passim.

110 ibid 84.

111 ibid.

${ }^{112}$ P Hunt, Human Rights, Health and Harm Reduction: States' Amnesia and Parallel Universes (2008), 8.
} 
way that renders certain drugs illicit. ${ }^{113}$ As the commentators observe, there are many human rights violations which 'occur as a result of drug policy'. ${ }^{114}$ It is true that Hunt goes on to argue that the illicit drugs framework should 'respect' 115 the operation of human rights law, but this is argued to be nothing more than an axiomatic point.

Human rights norms are enshrined in Treaties to which States are committed, and thus there is a requirement that such respect such be given. The problem, it is argued, is that Hunt fails to make the link between the creation of a role for international law in the regulation of drugs and the infringement of human rights. Again, it is true that Hunt highlights that harm reduction is a goal of the framework ${ }^{116}$ and one which he claims is not sufficiently promoted by States, ${ }^{117}$ but he fails to recognise that because the drug control regime may itself undermine human rights then it is not sufficient to treat the regimes as truly distinct. Rather than it being enough to ensure that the anti-drugs framework is exercised with respect for human rights norms in mind, it is argued that the framework must be developed in a way which does not itself contravene human rights.

One therefore finds the assertions of Golichenko and his colleagues persuasive in their recognition of this interplay and suggestion that an effective framework must not only be underpinned by harm reduction, but in fact must itself not cause harm to human

\footnotetext{
${ }^{113}$ M Golichenko, S Stolz and T Ezer, 'Addressing Human Rights Abuses Against People Who Use Drugs: A Critical Role for Human Rights Treaty Bodies and Special Procedures' (2018) 10 Journal of Human Rights Practice 83-102, 84.

114 ibid.

${ }^{115}$ P Hunt, Human Rights, Health and Harm Reduction: States' Amnesia and Parallel Universes (2008), 8.

116 ibid passim.

117 ibid.
} 
rights, or indeed in any other way. ${ }^{118}$ It is therefore argued that the role international law should take in regulating the use of drugs for non-medicinal purposes is one which recognises the societal harm which may result from such use and seeks to mitigate that harm with the minimum intervention with autonomous choices. In terms of what the framework should comprise, there must be recognition that rendering drugs illicit has the potential to cause a number of harms and these must be mitigated by the framework to protect human rights, and ensure that rather than just mitigating harms associated with drug use, the framework does not itself create additional harms and thus become self-defeating.

${ }^{118}$ M Golichenko, S Stolz and T Ezer, 'Addressing Human Rights Abuses Against People Who Use Drugs: A Critical Role for Human Rights Treaty Bodies and Special Procedures' (2018) 10 Journal of Human Rights Practice 83-102, 85. 


\section{Summary and Conclusion}

The international framework which aims to combat illicit drugs, whilst not considered in terms of its content, has been shown to be based on a flawed premise. As a harm prevention tool, it unjustifiably fails to include other substances, notably alcohol, which cause objectively more harm than the drugs made illicit under the regime, which is instead based on the moral views of Western States during the 1960s. Further, it has been shown that the very act of criminalising drugs may cause harm and there is thus an apparent irony between the objectives of a framework which aims to reduce harms, and in fact creates them. However, this does not mean that there should not be a role for international law in the context of drugs used for non-medicinal purposes. Here, it has been shown that the aim of the law should be to ensure co-operation where appropriate to enable States to take action to mitigate the problems associated with such drug use where this is necessary, whilst recognising the value of individual choice to use drugs, without this being considered problematic under the framework. The law should aim to protect human rights, and recognise that it is not enough for the antidrugs framework to be exercised in accordance with human rights norms, but it should also contain mechanisms to ensure that it is not itself contributing to violations of human rights. 